\title{
Venting and leaking of methane from shale gas development: response to Cathles et al.
}

\author{
Robert W. Howarth • Renee Santoro • \\ Anthony Ingraffea
}

Received: 10 December 2011 / Accepted: 10 January 2012 / Published online: 1 February 2012

(C) The Author(s) 2012. This article is published with open access at Springerlink.com

\begin{abstract}
In April 2011, we published the first comprehensive analysis of greenhouse gas (GHG) emissions from shale gas obtained by hydraulic fracturing, with a focus on methane emissions. Our analysis was challenged by Cathles et al. (2012). Here, we respond to those criticisms. We stand by our approach and findings. The latest EPA estimate for methane emissions from shale gas falls within the range of our estimates but not those of Cathles et al. which are substantially lower. Cathles et al. believe the focus should be just on electricity generation, and the global warming potential of methane should be considered only on a 100 -year time scale. Our analysis covered both electricity (30\% of US usage) and heat generation (the largest usage), and we evaluated both 20- and 100-year integrated time frames for methane. Both time frames are important, but the decadal scale is critical, given the urgent need to avoid climate-system tipping points. Using all available information and the latest climate science, we conclude that for most uses, the GHG footprint of shale gas is greater than that of other fossil fuels on time scales of up to 100 years. When used to generate electricity, the shale-gas footprint is still significantly greater than that of coal at decadal time scales but is less at the century scale. We reiterate our conclusion from our April 2011 paper that shale gas is not a suitable bridge fuel for the 21 st Century.
\end{abstract}

\section{Introduction}

Promoters view shale gas as a bridge fuel that allows continued reliance on fossil fuels while reducing greenhouse gas (GHG) emissions. Our April 2011 paper in Climatic Change challenged this view (Howarth et al. 2011). In the first comprehensive analysis of the GHG emissions from shale gas, we concluded that methane emissions lead to a large

Electronic supplementary material The online version of this article (doi:10.1007/s10584-012-0401-0) contains supplementary material, which is available to authorized users.

R. W. Howarth $(\bowtie) \cdot$ R. Santoro

Department of Ecology \& Evolutionary Biology, Cornell University, Ithaca, NY 14853, USA

e-mail: rwh2@cornell.edu

A. Ingraffea

School of Civil and Environmental Engineering, Cornell University, Ithaca, NY 14853, USA 
GHG footprint, particularly at decadal time scales. Cathles et al. (2012) challenged our work. Here, we respond to the criticisms of Cathles et al. (2012), and show that most have little merit. Further, we compare and contrast our assumptions and approach with other studies and with new information made available since our paper was published. After carefully considering all of these, we stand by the analysis and conclusions we published in Howarth et al. (2011).

\section{Methane emissions during entire life cycle for shale gas and conventional gas}

Cathles et al. (2012) state our methane emissions are too high and are "at odds with previous studies." We strongly disagree. Table 1 compares our estimates for both conventional gas and shale gas (Howarth et al. 2011) with 9 other studies, including 7 that have only become available since our paper was published in April 2011, listed chronologically by time of publication. See Electronic Supplementary Materials for details on conversions and calculations. Prior to our study, published estimates existed only for conventional gas. As we discussed in Howarth et al. (2011), the estimate of Hayhoe et al. (2002) is very close to our mean value for conventional gas, while the estimate from Jamarillo et al. (2007) is lower and should probably be considered too low because of their reliance on emission factors from a 1996 EPA report (Harrison et al. 1996). Increasing evidence over the past 15 years has suggested the 1996 factors were low (Howarth et al. 2011). In November 2010, EPA (2010) released parts of their first re-assessment of the 1996 methane emission factors, increasing some emissions factors by orders of magnitude. EPA (2011a), released just after our paper was published in April, used these new factors to re-assess and update the U.S. national GHG inventory, leading to a 2-fold increase in total methane emissions from the natural gas industry.

Table 1 Comparison of published estimates for full life-cycle methane emissions from conventional gas and shale gas, expressed per unit of Lower Heating Value $\left(\mathrm{gC} \mathrm{MJ}^{-1}\right)$. Studies are listed by chronology of publication date

\begin{tabular}{lcc}
\hline & Conventional gas & Shale gas \\
\hline Hayhoe et al. (2002) & 0.57 & $*$ \\
Jamarillo et al. (2007) & 0.15 & $*$ \\
Howarth et al. (2011) & $0.26-0.96$ & $0.55-1.2$ \\
EPA (2011a) & 0.38 & $0.60^{+}$ \\
Jiang et al. (2011) & $*$ & 0.30 \\
Fulton et al.(2011) & $0.38^{++}$ & $*$ \\
Hultman et al. (2011) & 0.35 & 0.57 \\
Skone et al. (2011) & 0.27 & 0.37 \\
Burnham et al. (2011) & 0.39 & 0.29 \\
Cathles et al. (2012) & $0.14-0.36$ & $0.14-0.36$ \\
\hline
\end{tabular}

See Electronic Supplemental Materials for details on conversions

* Estimates not provided in these reports

${ }^{+}$Includes emissions from coal-bed methane, and therefore may under-estimate shale gas emissions

${ }^{++}$Based on average for all gas production in the US, not just conventional gas, and so somewhat overestimates conventional gas emissions 
The new estimate for methane emissions from conventional gas in the EPA (2011a) inventory, $0.38 \mathrm{~g} \mathrm{C} \mathrm{MJ}^{-1}$, is within the range of our estimates: 0.26 to $0.96 \mathrm{~g} \mathrm{C} \mathrm{MJ}^{-1}$ (Table 1). As discussed below, we believe the new EPA estimate may still be too low, due to a low estimate for emissions during gas transmission, storage, and distribution. Several of the other recent estimates for conventional gas are very close to the new EPA estimate (Fulton et al. 2011; Hultman et al. 2011; Burnham et al. 2011). The Skone et al. (2011) value is $29 \%$ lower than the EPA estimate and is very similar to our lower-end number. Cathles et al. (2012) present a range of values, with their high end estimate of $0.36 \mathrm{~g} \mathrm{C} \mathrm{MJ}^{-1}$ being similar to the EPA estimate but their low end estimate $\left(0.14 \mathrm{~g} \mathrm{C} \mathrm{MJ}^{-1}\right)$ far lower than any other estimate, except for the Jamarillo et al. (2007) estimate based on the old 1996 EPA emission factors.

For shale gas, the estimate derived from EPA (2011a) of $0.60 \mathrm{~g} \mathrm{C} \mathrm{MJ}^{-1}$ is within our estimated range of 0.55 to $1.2 \mathrm{~g} \mathrm{C} \mathrm{MJ}^{-1}$ (Table 1); as with conventional gas, we feel the EPA estimate may not adequately reflect methane emissions from transmission, storage, and distribution. Hultman et al. (2011) provide an estimate only slightly less than the EPA number. In contrast, several other studies present shale gas emission estimates that are 38\% (Skone et al. 2011) to 50\% lower (Jiang et al. 2011; Burnham et al. 2011) than the EPA estimate. The Cathles et al. (2012) emission estimates are $40 \%$ to $77 \%$ lower than the EPA values, and represent the lowest estimates given in any study.

In an analysis of a PowerPoint presentation by Skone that provided the basis for Skone et al. (2011), Hughes (2011a) concludes that a major difference between our work and that of Skone and colleagues was the estimated lifetime gas production from a well, an important factor since emissions are normalized to production. Hughes (2011a) suggests that Skone significantly overestimated this lifetime production, and thereby underestimated the emissions per unit of energy available from gas production (see Electronic Supplemental Materials). We agree, and believe this criticism also applies to Jiang et al. (2011). The lifetime production of shale-gas wells remains uncertain, since the shale-gas technology is so new (Howarth and Ingraffea 2011). Some industry sources estimate a 30-year lifetime, but the oldest shale-gas wells from high-volume hydraulic fracturing are only a decade old, and production of shale-gas wells falls off much more rapidly than for conventional gas wells. Further, increasing evidence suggests that shale-gas production often has been exaggerated (Berman 2010; Hughes 2011a, 2011b; Urbina 2011a, 2011b).

Our high-end methane estimates for both conventional gas and shale gas are substantially higher than EPA (2011a) (Table 1), due to higher emission estimates for gas storage, transmission, and distribution ("downstream" emissions). Note that our estimated range for emissions at the shale-gas wells ("upstream" emissions of 0.34 to $0.58 \mathrm{~g} \mathrm{C} \mathrm{MJ}^{-1}$ ) agree very well with the EPA estimate $\left(0.43 \mathrm{~g} \mathrm{C} \mathrm{MJ}^{-1}\right.$; see Electronic Supplementary Materials). While EPA has updated many emission factors for natural gas systems since 2010 (EPA 2010, 2011a, 2011b), they continue to rely on the 1996 EPA study for downstream emissions. Updates to this assumption currently are under consideration (EPA 2011a). In the meanwhile, we believe the EPA estimates are too low (Howarth et al. 2011). Note that the downstream emission estimates of Hultman et al. (2011) are similar to EPA (2011a), while those of Jiang et al. (2011) are 43\% less, Skone et al. (2011) 38\% less, and Burnham et al. (2011) 31\% less (Electronic Supplemental Materials). One problem with the 1996 emission factors is that they were not based on random sampling or a comprehensive assessment of actual industry practices, but rather only analyzed emissions from model facilities run by companies that voluntarily participated (Kirchgessner et al. 1997). The average long-distance gas transmission pipeline in the U.S. is more than 50 years old, and many cities rely on gas distribution systems that are 80 to 100 years old, but these older 
systems were not part of the 1996 EPA assessment. Our range of estimates for methane emissions during gas storage, transmission, and distribution falls well within the range given by Hayhoe et al. (2002), and our mean estimate is virtually identical to their "best estimate" (Howarth et al. 2011). Nonetheless, we readily admit that these estimates are highly uncertain. There is an urgent need for better measurement of methane fluxes from all parts of the natural gas industry, but particularly during completion of unconventional wells and from storage, transmission, and distribution sectors (Howarth et al. 2011).

EPA proposed new regulations in October 2009 that would require regular reporting on GHG emissions, including methane, from natural gas systems (EPA 2011c). Chesapeake Energy Corporation, the American Gas Association, and others filed legal challenges to these regulations (Nelson 2011). Nonetheless, final implementation of the regulations seems likely. As of November 2011, EPA has extended the deadline for the first reporting to September 2012 (EPA 2011c). These regulations should help evaluate methane pollution, although actual measurements of venting and leakage rates will not be required, and the reporting requirement as proposed could be met using EPA emission factors. Field measurements across a range of well types, pipeline and storage systems, and geographic locations are important for better characterizing methane emissions.

\section{How much methane is vented during completion of shale-gas wells?}

During the weeks following hydraulic fracturing, frac-return liquids flow back to the surface, accompanied by large volumes of natural gas. We estimated substantial methane venting to the atmosphere at this time, leading to a higher GHG footprint for shale gas than for conventional gas (Howarth et al. 2011). Cathles et al. (2012) claim we are wrong and assert that methane emissions from shale-gas and conventional gas wells should be equivalent. They provide four arguments: 1) a physical argument that large flows of gas are not possible while frac fluids fill the well; 2) an assertion that venting of methane to the atmosphere would be unsafe; 3 ) a statement that we incorrectly used data on methane capture during flowback to estimate venting; and 4) an assertion that venting of methane is not in the economic interests of industry. We disagree with each point, and note our methane emission estimates during well completion and flowback are quite consistent with both those of EPA (2010, 2011a, b) and Hultman et al. (2011).

Cathles et al. state that gas venting during flowback is low, since the liquids in the well interfere with the free flow of gas, and imply that this condition continues until the well goes into production. While it is true that liquids can restrict gas flow early in the flow-back period, gas is freely vented in the latter stages. According to EPA (2011d), during well cleanup following hydraulic fracturing "backflow emissions are a result of free gas being produced by the well during well cleanup event, when the well also happens to be producing liquids (mostly water) and sand. The high rate backflow, with intermittent slugs of water and sand along with free gas, is typically directed to an impoundment or vessels until the well is fully cleaned up, where the free gas vents to the atmosphere while the water and sand remain in the impoundment or vessels." The methane emissions are "vented as the backflow enters the impoundment or vessels" (EPA 2011d). Initial flowback is $100 \%$ liquid, but this quickly becomes a two-phase flow of liquid and gas as backpressure within the fractures declines (Soliman \& Hunt 1985; Willberg et al. 1998; Yang et al. 2010; EPA 2011a, d). The gas produced is not in solution, but rather is free-flowing with the liquid in this frothy mix. The gas cannot be put into production and sent to sales until flowback rates are sufficiently decreased to impose pipeline pressure. 
Is it unsafe for industry to vent gas during flowback, as Cathles et al. assert? Perhaps, but venting appears to be common industry practice, and the latest estimates from EPA (2011b, page $3-12$ ) are that $85 \%$ of flowback gas from unconventional wells is vented and less than $15 \%$ flared or captured. While visiting Cornell, a Shell engineer stated Shell never flares gas during well completion in its Pennsylvania Marcellus operations (Bill Langin, pers. comm.). Venting of flow-back methane is clearly not as unsafe as Cathles et al. (2012) believe, since methane has a density that is only $58 \%$ that of air and so would be expected to be extremely buoyant when vented. Under sufficiently high wind conditions, vented gas may be mixed and advected laterally rather than rising buoyantly, but we can envision no atmospheric conditions under which methane would sink into a layer over the ground. Buoyantly rising methane is clearly seen in Forward Looking Infra Red (FLIR) video of a Pennsylvania well during flowback (Fig. 1). Note that we are not using this video information to infer any information on the rate of venting, but simply to illustrate that venting occurred in the summer of 2011 in Pennsylvania and that the gas rose rapidly into the atmosphere. Despite the assertion by Cathles et al. that venting is illegal in Pennyslvania, the only legal restriction is that "excess gas encountered during drilling, completion or stimulation shall be flared, captured, or diverted away from the drilling rig in a manner than does not create a hazard to the public health or safety" (PA $§ 78.73$. General provision for well construction and operation).

Cathles et al. state with regard to our paper: "The data they cite to support their contention that fugitive methane emissions from unconventional gas production is [sic] significantly greater than that from conventional gas production are actually estimates of gas emissions that were captured for sale. The authors implicitly assume that capture (or even flaring) is rare, and that the gas captured in the references they cite is normally vented directly into the atmosphere." We did indeed use data on captured gas as a surrogate for vented emissions, similar to such interpretation by EPA (2010). Although most flowback gas appears to be vented and not captured (EPA 2011b), we are aware of no data on the rate of venting, and industry apparently does not usually measure or estimate the gas that is vented during flowback. Our assumption (and that of EPA 2010) is that the rate of gas flow is the same during flowback, whether vented or captured. Most of the data we used were reported to the EPA as part of their "green completions" program, and they provide some of the very few publicly available quantitative estimates of methane flows at the time of flowback. Note that the estimates we published in Howarth et al. (2011) for emissions at the time of well completion for shale gas could be reduced by $15 \%$, to account for the estimated average percentage of gas that is not vented but

Fig. 1 Venting of natural gas into the atmosphere at the time of well completion and flowback following hydraulic fracturing of a well in Susquehanna County, PA, on June 22, 2011. Note that this gas is being vented, not flared or burned, and the color of the image is to enhance the IR image of this methane-tuned FLIR imagery. The full video of this event is available at http://www. psehealthyenergy.org/resources/ view/198782. Video provided courtesy of Frank Finan

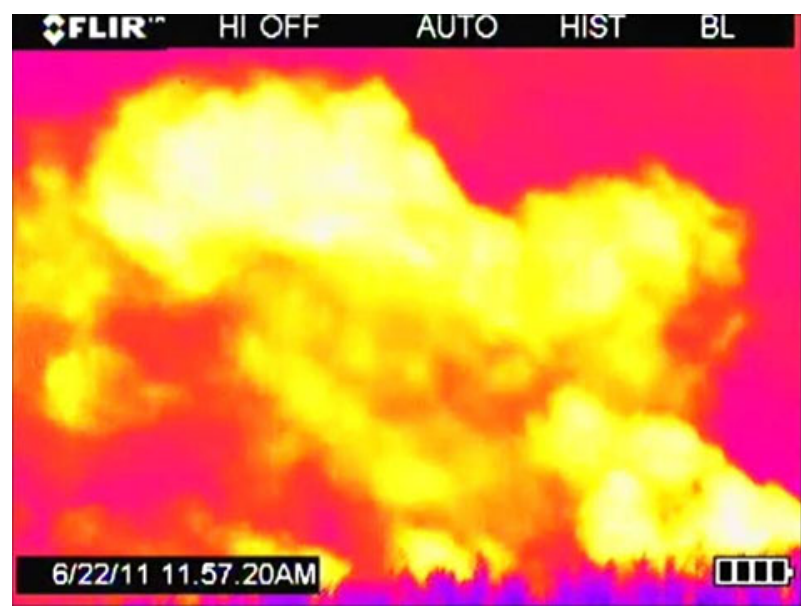


rather is flared or captured and sold (EPA 2011b). Given the other uncertainty in these estimates, though, our conclusions would remain the same.

Cathles et al. also assert that we used initial production rates for gas wells, and that in doing so over-estimated flowback venting. Our estimates of flowback emissions for the Barnett, Piceance, Uinta, and Denver-Jules basins were not based on initial production rates, but rather solely on industry-reported volumes of gas captured, assuming. We estimated emissions for the Haynesville basin as the median of data given in Eckhardt et al. (2009), who reported daily rates ranging from $400,000 \mathrm{~m}^{3}$ (14 MMcf) to $960,000 \mathrm{~m}^{3}$ (38 MMcf). We assumed a 10-day period for the latter part of the flowback in which gases freely flow, the mean for the other basin studies we used. The use of initial production rates applied to the latter portion of flowback duration as an estimate of venting is commonly accepted (Jiang et al. 2011; NYS DEC 2011).

Finally, Cathles et al. state that economic self-interest would make venting of gas unlikely. Rather, they assert industry would capture the gas and sell it to market. According to EPA (2011b), the break-even price at which the cost of capturing flowback gas equals the market value of the captured gas is slightly under $\$ 4$ per thousand cubic feet. This is roughly the wellhead price of gas over the past two years, suggesting that indeed industry would turn a profit by capturing the gas, albeit a small one. Nonetheless, EPA (2011b) states that industry is not commonly capturing the gas, probably because the rate of economic return on investment for doing so is much lower than the normal expectation for the industry. That is, industry is more likely to use their funds for more profitable ventures than capturing and selling vented gas (EPA 2011b). There also is substantial uncertainty in the cost of capturing the gas. At least for lowenergy wells, a BP presentation put the cost of "green" cleanouts as 30\% higher than for normal well completions (Smith 2008). The value of the captured gas would roughly pay for the process, according to BP, at the price of gas as of 2008 , or approximately $\$ 6.50$ per thousand cubic feet (EIA 2011a). At this cost, industry would lose money by capturing and selling gas not only at the current price of gas but also at the price forecast for the next 2 decades (EPA 2011b).

In July 2011, EPA (2011b, e) proposed new regulations to reduce emissions during flowback. The proposed regulation is aimed at reducing ozone and other local air pollution, but would also reduce methane emissions. EPA (2011b, e) estimates the regulation would reduce flowback methane emissions from shale gas wells by up to $95 \%$, although gas capture would only be required for wells where collector pipelines are already in place, which is often not the case when new sites are developed. Nonetheless, this is a very important step, and if the regulation is adopted and can be adequately enforced, will reduce greatly the difference in emissions between shale gas and conventional gas in the U.S. We urge universal adoption of gas-capture policies.

To summarize, most studies conclude that methane emissions from shale gas are far higher than from conventional gas: approximately $40 \%$ higher, according to Skone et al. (2011) and using the mean values from Howarth et al. (2011), and approximately 60\% higher using the estimates from EPA (2011a) and Hultman et al. (2011). Cathles et al. assertion that shale gas emissions are no higher seems implausible to us. The suggestion by Burnham et al. (2011) that shale gas methane emissions are less than for conventional gas seems even less plausible (see Electronic Supplementary Materials).

\section{Time frame and global warming potential of methane}

Methane is a far more powerful GHG than carbon dioxide, although the residence time for methane in the atmosphere is much shorter. Consequently, the time frame for comparing 
methane and carbon dioxide is critical. In Howarth et al. (2011), we equally presented two time frames, the 20 and 100 years integrated time after emission, using the global warming potential (GWP) approach. Note that GWPs for methane have only been estimated at time scales of 20,100, and 500 years, and so GHG analyses that compare methane and carbon dioxide on other time scales require a more complicated atmospheric modeling approach, such as that used by Hayhoe et al. (2002) and Wigley (2011). The GWP approach we follow is quite commonly used in GHG lifecycle analyses, sometimes considering both 20-year and 100-year time frames as we did (Lelieveld et al. 2005; Hultman et al. 2011), but quite commonly using only the 100-year time frame (Jamarillo et al. 2007; Jiang et al. 2011; Fulton et al. 2011; Skone et al. 2011; Burnham et al. 2011). Cathles et al. state that a comparison based on the 20-year GWP is inappropriate, and criticize us for having done so. We very strongly disagree.

Considering methane's global-warming effects at the decadal time scale is critical (Fig. 2). Hansen et al. (2007) stressed the need for immediate control of methane to avoid critical tipping points in the Earth's climate system, particularly since methane release from permafrost becomes increasingly likely as global temperature exceeds $1.8^{\circ} \mathrm{C}$ above the

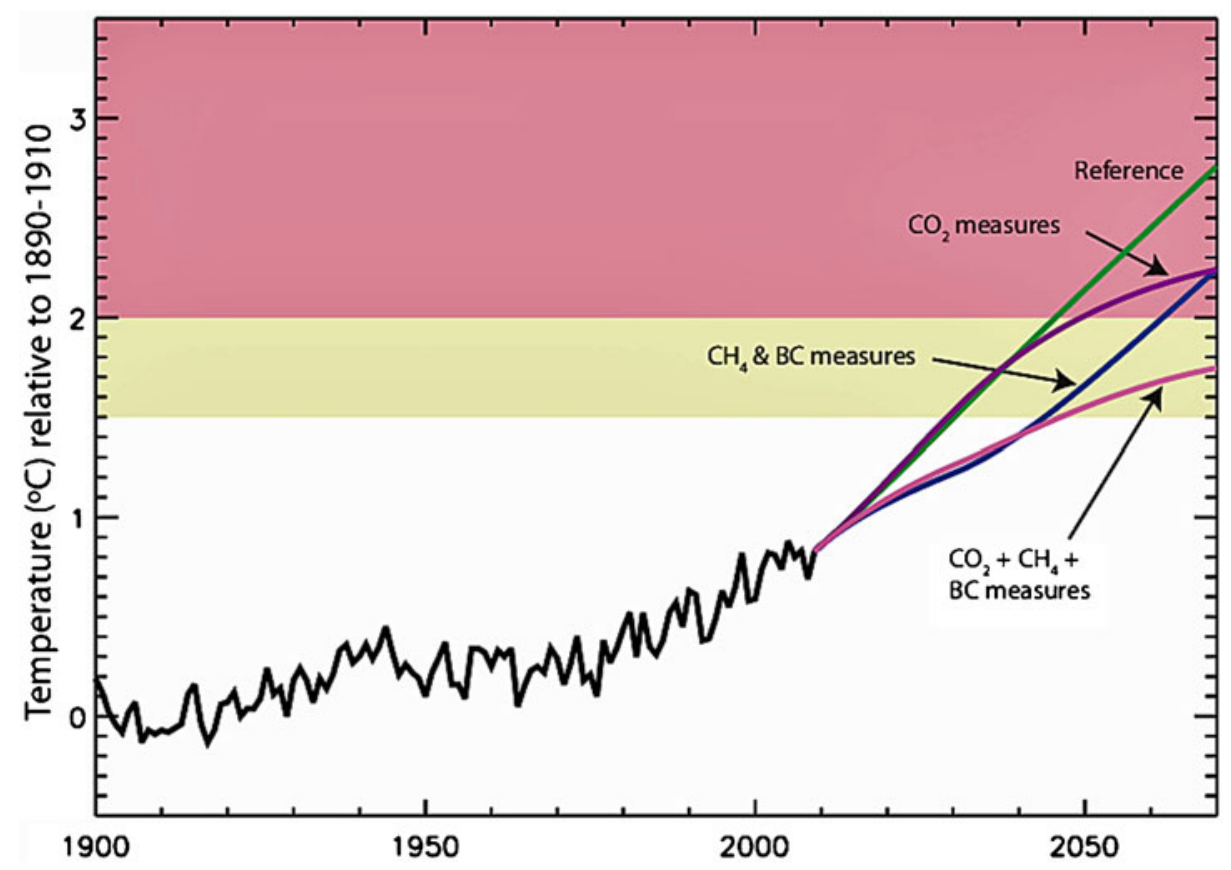

Fig. 2 Observed global mean temperature from 1900 to 2009 and projected future temperature under four scenarios, relative to the mean temperature from 1890-1910. The scenarios include the IPCC (2007) reference, reducing carbon dioxide emissions but not other greenhouse gases (" $\mathrm{CO}_{2}$ measures"), controlling methane and black carbon emissions but not carbon dioxide (" $\mathrm{CH}_{4}+\mathrm{BC}$ measures"), and reducing emissions of carbon dioxide, methane, and black carbon (" $\mathrm{CO}_{2}+\mathrm{CH}_{4}+\mathrm{BC}$ measures"). An increase in the temperature to $1.5^{\circ}$ to $2.0^{\circ} \mathrm{C}$ above the $1890-1910$ baseline (illustrated by the yellow bar) poses high risk of passing a tipping point and moving the Earth into an alternate state for the climate system. The lower bound of this danger zone, $1.5^{\circ}$ warming, is predicted to occur by 2030 unless stringent controls on methane and black carbon emissions are initiated immediately. Controlling methane and black carbon shows more immediate results than controlling carbon dioxide emissions, although controlling all greenhouse gas emissions is essential to keeping the planet in a safe operating space for humanity. Reprinted from UNEP/WMO (2011) 
baseline average temperature between 1890 and 1910 (Hansen and Sato 2004; Hansen et al. 2007). This could lead to a rapidly accelerating positive feedback of further global warming (Zimov et al. 2006; Walter et al. 2007). Shindell et al. (2012) and a recent United Nations study both conclude that this $1.8^{\circ} \mathrm{C}$ threshold may be reached within 30 years unless societies take urgent action to reduce the emissions of methane and other short-lived greenhouse gases now (UNEP/WMO 2011). The reports predict that the lower bound for the danger zone for a temperature increase leading to climate tipping points $-\mathrm{a} 1.5^{\circ} \mathrm{C}$ increase - will occur within the next 18 years or even less if emissions of methane and other short-lived radiatively active substances such as black carbon are not better controlled, beginning immediately (Fig. 2) (Shindell et al. 2012; UNEP/WMO 2011).

In addition to different time frames, studies have used a variety of GWP values. We used values of 105 and 33 for the 20- and 100-year integrated time frames, respectively (Howarth et al. 2011), based on the latest information on methane interactions with other radiatively active materials in the atmosphere (Shindell et al. 2009). Surprisingly, EPA (2011a) uses a value of 21 based on IPCC (1995) rather than higher values from more recent science (IPCC 2007; Shindell et al. 2009). Jiang et al. (2011), Fulton et al. (2011), Skone et al. (2011), and Burnham et al. (2011) all used the 100-year GWP value of 25 from IPCC (2007), which underestimates methane's warming at the century time scale by $33 \%$ compared to the more recent GWP value of 33 from Shindell et al. (2009). We stand by our use of the higher GWP values published by Shindell et al. (2009), believing it appropriate to use the best and most recent science. While there are considerable uncertainties in GWP estimates, inclusion of the suppression of photosynthetic carbon uptake due to methaneinduced ozone (Sitch et al. 2007) would further increase methane's GWP over all the values discussed here.

In Fig. 3, we present the importance of methane to the total GHG inventory for the US, considered at both the 20- and 100-year time periods, and using the Shindell et al. (2009) GWP values. Figure 3 uses the most recently available information on methane fluxes for the 2009 base year, reflecting the new methane emission factors and updates through July 2011 (EPA 2010; 2011a, b); see Electronic Supplemental Materials. Natural gas systems dominate the methane flux for the US, according to these EPA estimates, contributing 39\% of the nation's total. And methane contributes $19 \%$ of the entire GHG inventory of the US at the century time scale and $44 \%$ at the 20 -year scale, including all gases and all human activities. The methane emissions from natural gas systems make up $17 \%$ of the entire anthropogenic GHG inventory of the US, when viewed through the lens of the 20 -year integrated time frame. If our high-end estimate for downstream methane emissions during gas storage, transmission, and distribution is correct (Howarth et al. 2011), the importance of methane from natural gas systems would be even greater.

\section{Electricity vs. other uses}

Howarth et al. (2011) focused on the GHG footprint of shale gas and other fuels normalized to heat from the fuels, following Lelieveld et al. (2005) for conventional gas. We noted that for electricity generation - as opposed to other uses of natural gas - the greater efficiency for gas shifts the comparison somewhat, towards the footprint of gas being less unfavorable. Nonetheless, we concluded shale gas has a larger GHG footprint than coal even when used to generate electricity, at the 20-year time horizon (Howarth et al. 2011). Hughes (2011b) further explored the use of shale gas for electricity generation, and supported our conclusion. Cathles et al. criticize us for not focusing exclusively on electricity. 


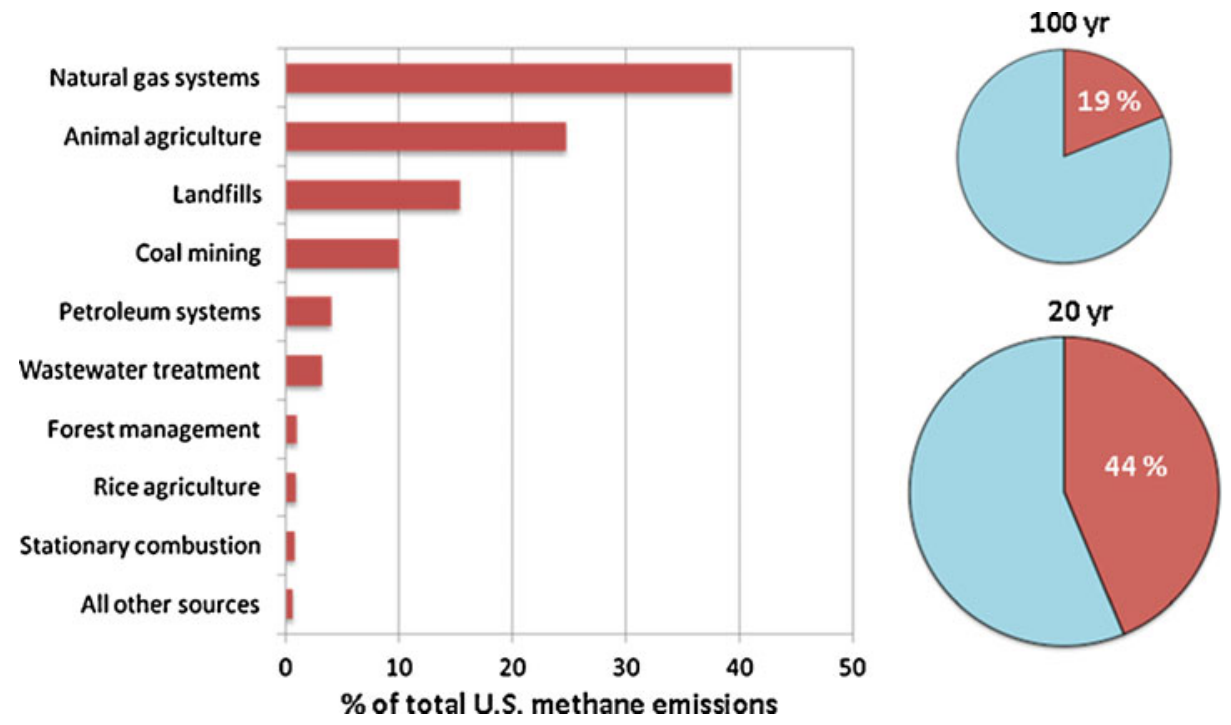

Fig. 3 Environmental Protection Agency estimates for human-controlled sources of methane emission from the U.S. in 2009 (bar graph) and percent contribution of methane to the entire greenhouse gas inventory for the U.S. (shown in red on the pie charts) for the 100-year and 20-year integrated time scales. The sizes of the pie charts are proportional to the total greenhouse gas emission for the U.S. in 2009. The methane emissions represent a greater portion of the warming potential when converted to equivalents of mass of carbon dioxide at the shorter time scale, which increases both the magnitude of the total warming potential and the percentage attributed to methane. Data are from EPA (2011a, b), as discussed in Electronic Supplemental Material, and reflect an increase over the April 2011 national inventory estimates due to new information on methane emissions from Marcellus shale gas and tight-sand gas production for 2009 (EPA 2011b). Animal agriculture estimate combines enteric fermentation with manure management. Coal mining combines active mines and abandoned mines. The time-frame comparisons are made using the most recent data on global warming potentials from Shindell et al. (2009)

We stand by our focus on GHG emissions normalized to heat content. Only $30 \%$ of natural gas in the U.S. is used to generate electricity, while most is used for heat for domestic, commercial, and industrial needs, and this pattern is predicted to hold over coming decades (EIA 2011b; Hughes 2011b). Globally, demand for heat is the largest use of energy, at $47 \%$ of use (International Energy Agency 2011). And natural gas is the largest source of heat globally, providing over half of all heat needs in developed countries (International Energy Agency 2011). While generating electricity from natural gas has some efficiency gains over using coal, we are aware of no such advantage for natural gas over other fossil fuels for providing heat.

Many view use of natural gas for transportation as an important part of an energy future. The "Natural Gas Act" (H.R.1380) introduced in Congress in 2011 with bipartisan support and the support of President Obama would provide tax subsidies to encourage long-distance trucks to switch from diesel to natural gas (Weiss and Boss 2011). And in Quebec, industry claims converting trucks from diesel to shale gas could reduce GHG emissions by 25 to $30 \%$ (Beaudine 2010). Our study suggests this claim is wrong and indicates shale gas has a larger GHG footprint than diesel oil, particularly over the 20-year time frame (Howarth et al. 2011). In fact, using natural gas for long-distance trucks may be worse than our analysis suggested, since it would likely depend on liquefied natural gas, LNG. GHG emissions from LNG are far higher than for non-liquified gas (Jamarillo et al. 2007). See Electronic Supplemental Materials for more information on future use of natural gas in the U.S. 


\section{Conclusions}

We stand by our conclusions in Howarth et al. (2011) and see nothing in Cathles et al. and other reports since April 2011 that would fundamentally change our analyses. Our methane emission estimates compare well with EPA (2011a), although our high-end estimates for emissions from downstream sources (storage, transmission, distribution) are higher. Our estimates also agree well with earlier papers for conventional gas (Hayhoe et al. 2002; Lelieveld et al. 2005), including downstream emissions. Several other analyses published since April of 2011 have presented significantly lower emissions than EPA estimates for shale gas, including Cathles et al. but also Jiang et al. (2011), Skone et al. (2011), and Burnham et al. (2011). We believe these other estimates are too low, in part due to overestimation of the lifetime production of shale-gas wells.

We reiterate that all methane emission estimates, including ours, are highly uncertain. As we concluded in Howarth et al. (2011), "the uncertainty in the magnitude of fugitive emissions is large. Given the importance of methane in global warming, these emissions deserve far greater study than has occurred in the past. We urge both more direct measurements and refined accounting to better quantify lost and unaccounted for gas." The new GHG reporting requirements by EPA will provide better information, but much more is needed. Governments should encourage and fund independent measurements of methane venting and leakage. The paucity of such independent information is shocking, given the global significance of methane emissions and the potential scale of shale gas development.

We stress the importance of methane emissions on decadal time scales, and not focusing exclusively on the century scale. The need for controlling methane is simply too urgent, if society is to avoid tipping points in the planetary climate system (Hansen et al. 2007; UNEP/WMO 2011; Shindell et al. 2012). Our analysis shows shale gas to have a much larger GHG footprint than conventional natural gas, oil, or coal when used to generate heat and viewed over the time scale of 20 years (Howarth et al. 2011). This is true even using our low-end methane emission estimates, which are somewhat lower than the new EPA (2011a) values and comparable to those of Hultman et al. (2011). At this 20-year time scale, the emissions data from EPA (2011a, b) show methane makes up $44 \%$ of the entire GHG inventory for the U.S., and methane from natural gas systems make up $17 \%$ of the entire GHG inventory (39\% of the methane component of the inventory).

We also stress the need to analyze the shale-gas GHG footprint for all major uses of natural gas, and not focus on the generation of electricity alone. Of the reports published since our study, only Hughes (2011b) seriously considered heat as well as electricity. Cathles et al. (2012), Jiang et al. (2011), Fulton et al. (2011), Hultman et al. (2011), Skone et al. (2011), and Wigley (2011) all focus just on the generation of electricity. We find this surprising, since only $30 \%$ of natural gas in the U.S. is used to generate electricity. Other uses such as transportation should not be undertaken without fully understanding the consequences on GHG emissions, and none of the electricity-based studies provide an adequate basis for such evaluation.

Can shale-gas methane emissions be reduced? Clearly yes, and proposed EPA regulations to require capture of gas at the time of well completions are an important step. Regulations are necessary to accomplish emission reductions, as economic considerations alone have not driven such reductions (EPA 2011b). And it may be extremely expensive to reduce leakage associated with aging infrastructure, particularly distribution pipelines in cities but also longdistance transmission pipelines, which are on average more than 50 years old in the U.S. Should society invest massive capital in such improvements for a bridge fuel that is to be used for only 20 to 30 years, or would the capital be better spent on constructing a smart electric grid and other technologies that move towards a truly green energy future? 
We believe the preponderance of evidence indicates shale gas has a larger GHG footprint than conventional gas, considered over any time scale. The GHG footprint of shale gas also exceeds that of oil or coal when considered at decadal time scales, no matter how the gas is used (Howarth et al. 2011; Hughes 2011a, b; Wigley et al. 2011). Considered over the century scale, and when used to generate electricity, many studies conclude that shale gas has a smaller GHG footprint than coal (Wigley 2011; Hughes 2011b; Hultman et al. 2011), although some of these studies biased their result by using a low estimate for GWP and/or low estimates for methane emission (Jiang et al. 2011; Skone et al. 2011; Burnham et al. 2011). However, the GHG footprint of shale gas is similar to that of oil or coal at the century time scale, when used for other than electricity generation. We stand by the conclusion of Howarth et al. (2011): "The large GHG footprint of shale gas undercuts the logic of its use as a bridging fuel over coming decades, if the goal is to reduce global warming."

Acknowledgements We thank Terry Chapin, Chris Costello, Jon Foley, David Hughes, Amy Mall, Roxanne Marino, Nathan Phillips, and Drew Shindell for comments and advice. Funding was provided by the Park Foundation and endowments given by David. R. Atkinson and Dwight C. Baum to Cornell University. The authors have no financial conflict of interests.

Open Access This article is distributed under the terms of the Creative Commons Attribution License which permits any use, distribution, and reproduction in any medium, provided the original author(s) and the source are credited.

\section{References}

Beaudine M (2010) In depth: shale gas exploration in Quebec. The Gazette, November 15, 2010

Berman A (2010) Shale gas-Abundance or mirage? Why the Marcellus shale will disappoint expectations. The Oil Drum, Drumbeat, October 29, 2010. http://www.theoildrum.com/node/7079

Burnham A, Han J, Clark CE, Wang M, Dunn JB, and Rivera IP (2011) Life-cycle greenhouse gas emissions of shale gas, natural gas, coal, and petroleum. Environ Sci Technol. doi:10.1021/es201942m

Cathles LM, Brown L, Taam M, Hunter A (2012) this volume

Eckhardt M, Knowles B, Maker E, Stork P (2009) IHS U.S Industry Highlights. (IHS) Houston TX. Feb-Mar 2009. http://www.gecionline.com/2009-prt-7-final-reviews

EIA (2011a) U.S. Natural Gas Wellhead Price (Dollars per Thousand Cubic Feet). U.S. Department of Energy, Energy Information Agency http://www.eia.gov/dnav/ng/hist/n9190us3m.htm

EIA (2011b) Annual Energy Outlook 2011. U.S. Department of Energy, Energy Information Agency (released April 2011)

EPA (2010) Greenhouse Gas Emissions Reporting from the Petroleum and Natural Gas Industry. Background Technical Support Document. U.S. Environmental Protection Agency, Washington DC. http://www.epa. gov/climatechange/emissions/downloads10/Subpart-W_TSD.pdf

EPA (2011a) Inventory of U.S. Greenhouse Gas Emissions and Sinks: 1990-2009. April 14, 2011. U.S. Environmental Protection Agency, Washington DC. http://epa.gov/climatechange/emissions/usinventoryreport.html

EPA (2011b) Regulatory Impact Analysis: Proposed New Source Performance Standards and Amendments to the National Emissions Standards for Hazardous Air Pollutants for the Oil and Gas Industry. July 2011. U. S. Environmental Protection Agency, Office of Air and Radiation. Washington DC

EPA (2011c) Climate Change - Regulatory Initiatives. U.S. Environmental Protection Agency, Washington DC. http:/www.epa.gov/climatechange/emissions/ghgrulemaking.html (downloaded Nov. 22, 2011)

EPA (2011d) Oil and natural gas sector: standards of performance for crude oil and natural gas production, transmission, and distribution. EPA-453/R-11-002. Prepared for U.S. EPA Office of Air Quality Planning and Standards by EC/R Incorporated. U.S. Environmental Protection Agency, Washington DC

EPA (2011e) Proposed Amendments to Air Regulations for the Oil and Gas Industry Fact Sheet. U.S. Environmental Protection Agency, Washington DC. http://www.epa.gov/airquality/oilandgas/pdfs/ 20110728factsheet.pdf 
Fulton M, Mellquist N, Kitasei S, and Bluestein J (2011) Comparing greenhouse gas emissions from natural gas and coal. 25 Aug 2011. Worldwatch Institute/Deutsche Bank

Hansen J, Sato M (2004) Greenhouse gas growth rates. Proc Natl Acad Sci USA 101:16 109-16 114

Hansen J, Sato M, Kharecha P, Russell G, Lea DW, Siddall M (2007) Climate change and trace gases. Phil Trans R Soc A 365:1925-1954

Harrison MR, Shires TM, Wessels JK, Cowgill RM (1996) Methane emissions from the natural gas industry. Volume 1: executive summary. EPA-600/R-96-080a. U.S. Environmental Protection Agency, Office of Research and Development, Washington, DC

Hayhoe K, Kheshgi HS, Jain AK, Wuebbles DJ (2002) Substitution of natural gas for coal: climatic effects of utility sector emissions. Clim Chang 54:107-139

Howarth RW, Ingraffea A (2011) Should fracking stop? Yes, it is too high risk. Nature 477:271-273

Howarth RW, Santoro R, Ingraffea A (2011) Methane and the greenhouse gas footprint of natural gas from shale formations. Climatic Chang Lett. doi:10.1007/s10584-011-0061-5

Hughes D (2011a) Lifecycle greenhouse gas emissions from shale gas compared to coal: an analysis of two conflicting studies. Post Carbon Institute, Santa Rosa, http://www.postcarbon.org/reports/PCI-HughesNETL-Cornell-Comparison.pdf

Hughes D (2011b) Will Natural Gas Fuel America in the 21st Century? Post Carbon Institute, Santa Rosa, CA. http://www.postcarbon.org/report/331901-will-natural-gas-fuel-america-in

Hultman N, Rebois D, Scholten M, Ramig C (2011) The greenhouse impact of unconventional gas for electricity generation. Environ Res Lett 6:044008. doi:10.1088/1748-9326/6/4/044008

International Energy Agency (2011) Cogeneration and renewables: solutions for a low-carbon energy future. International Energy Agency, Paris

IPCC (1995) IPCC Second Assessment, Climate Change, 1995. http://www.ipcc.ch/pdf/climate-changes1995/ipcc-2nd-assessment/2nd-assessment-en.pdf

IPCC (2007) IPCC Fourth Assessment Report (AR4), Working Group 1, The Physical Science Basis. http:// www.ipcc.ch/publications_and_data/ar4/wg1/en/contents.html

Jamarillo P, Griffin WM, Mathews HS (2007) Comparative life-cycle air emissions of coal, domestic natural gas, LNG, and SNG for electricity generation. Environ Sci Technol 41:6290-6296

Jiang M, Griffin WM, Hendrickson C, Jaramillo P, vanBriesen J, Benkatesh A (2011) Life cycle greenhouse gas emissions of Marcellus shale gas. Environ Res Lett 6:034014. doi:10.1088/1748-9326/6/3/034014

Kirchgessner DA, Lott RA, Cowgill RM, Harrison MR, Shires TM (1997) Estimate of methane emissions from the US natural gas industry. Chemosphere 35:1365-1390

Lelieveld J, Lechtenbohmer S, Assonov SS, Brenninkmeijer CAM, Dinest C, Fischedick M, Hanke T (2005) Low methane leakage from gas pipelines. Nature 434:841-842

Nelson G (2011) Natural gas, electronics groups sue EPA. Energy Tribune. Feb. 2, 2011. http://www. energytribune.com/articles.cfm/6480/Natural-Gas-Electronics-Groups-Sue-EPA

NYS DEC (2011) SGEIS on the Oil, Gas and Solution Mining Regulatory Program: Well Permit Issuance for Horizontal Drilling and High-Volume Hydraulic Fracturing to Develop the Marcellus Shale and Other Low-Permeability Gas Reservoirs. Revised draft, Sept 2011. New York State Dept. of Environmental Conservation, Albany, NY

Shindell DT, Faluvegi G, Koch DM, Schmidt GA, Unger N, Bauer SE (2009) Improved attribution of climate forcing to emissions. Science 326:716-718

Shindell D, Kuylenstierna JCI, Vignati E, van Dingenen R, Amann M, Klimont Z, Anenberg SC, Muller N, Janssens-Maenhout G, Raes F, Schwartz J, Faluvegi G, Pozzoli L, Kupiainen K, Höglund-Isaksson L, Emberson L, Streets D, Ramanathan V, Hicks K, Oanh NTK, Milly G, Williams M, Demkine V, Fowler D (2012) Simultaneously mitigating near-term climate change and improving human health and food security. Science 335:183-189. doi:10.1126/science.1210026

Sitch S, Cox PM, Collins WJ, Huntingford C (2007) Indirect radiative forcing of climate change through ozone effects on the land-carbon sink. Nature 448:791-794

Skone TJ, Littlefield J, Marriott J (2011) Life cycle greenhouse gas inventory of natural gas extraction, delivery and electricity production. Final report 24 Oct 2011 (DOE/NETL-2011/1522). U.S. Department of Energy, National Energy Technology Laboratory, Pittsburgh, PA

Smith GR (2008) Reduced Emission (Green) Completion in Low Energy Reserves. BP America Production Company. $15^{\text {th }}$ Annual Natural Gas STAR Implementation Workshop, San Antonio TX, Nov. 11-13, 2008. http://www.epa.gov/gasstar/workshops/annualimplementation/2008.html

Soliman MY Hunt JL (1985) Effect of fracturing fluid and its cleanup on well performance. SPE 14514. Presented paper. SPE Regional Meeting, Morgantown WV, 6-8 Nov 1985

UNEP/WMO (2011) Integrated assessment of black carbon and tropospheric ozone: summary for decision makers. United Nations Environment Programme and the World Meteorological Organization, Nairobi 
Urbina I (2011a) Insiders sound an alarm amid a natural gas rush. New York Times, June 26, 2011. http:// www.nytimes.com/2011/06/26/us/26gas.html?_r=1\&ref=ianurbina

Urbina I (2011b) Behind veneer, doubts on natural gas. New York Times, June 26, 2011. http://www.nytimes. com/2011/06/27/us/27gas.html?ref=ianurbina

Walter KM, Smith LC, Chapin FS (2007) Methane bubbling from northern lakes: present and future contributions to the methane budget. Phil Trans R Soc A 365:1657-1676

Weis DJ, Boss S (2011) Conservatives Power Big Oil, Stall Cleaner Natural Gas Vehicles. Center for American Progress, June 6, 2011. http://www.americanprogress.org/issues/2011/06/nat_gas_statements. html

Wigley TML (2011) Coal to gas: the influence of methane leakage. Climatic Chang Lett. doi:10.1007/s10584011-0217-3

Willberg DM, Steinsberger N, Hoover R, Card RJ, Queen J (1998) Optimization of fracture cleanup using flowback analysis. SPE 39920. Presented paper. SPE Rocky Mountain Regional/ Low-permeability Reservoirs Symposium and Exhibition, Denver CO, 5-8 April 1998

Yang JY, Holditch SA, McVay DA (2010) Modeling fracture-fluid cleanup in tight-gas wells. Paper SPE 119624, SPE Journal 15(3)

Zimov SA, Schuur EAG, Chapin FS (2006) Permafrost and the global carbon budget. Science 312:1612-1613 